\title{
Sistem Kontrol Frekuensi Optimal Pada Pembangkit Hibrid Wind-Diesel Dengan Imperialist Competitive Algorithm
}

\author{
Muhammad Ruswandi Djalal ${ }^{1, *)}$, Andi Imran $^{2)}$, Herlambang Setiadi ${ }^{3)}$ \\ ${ }^{1)}$ Program Studi Teknik Energi, Jurusan Teknik Mesin, Politeknik Negeri Ujung Pandang \\ Jalan Perintis Kemerdekaan km.10 Makassar 90245 \\ 2) Jurusan Teknik Elektro, Fakultas Teknologi Industri, Institut Teknologi Sepuluh Nopember \\ Jalan Raya ITS, Kampus ITS Sukolilo, Surabaya 60111 \\ ${ }^{3)}$ School of Information Technology \& Electrical Engineering, The University of Queensland \\ Brisbane, Australia
}

\begin{abstract}
Cara sitasi: M. R. Djalal, A. Imran, and H. Setiadi, "Sistem Kontrol Frekuensi Optimal Pada Pembangkit Hibrid Wind-Diesel Dengan Imperialist Competitive Algorithm," Jurnal Teknologi dan Sistem Komputer, vol. 5, no. 4, pp. 135-141, Okt. 2017. doi: 10.14710/jtsiskom.5.4.2017.135-141, [Online].
\end{abstract}

\begin{abstract}
Frequency load arrangement on wind-diesel hybrid power plants (PLTH) becomes a very important thing in order to support the performance of the plant. One method of setting the load frequency is to use additional controllers such as Proportional Integral Derivative (PID). The use of PID also has its own problems, such as adjusting the value of unoptimal gain. In practice the PID gain is observed by trialerror, making it difficult to obtain the optimal value of the PID. In this research, we proposed an intelligent method of Imperialist Competitive Algorithm (ICA) in finding the optimal value of PID. The ICA is a smart method inspired by the competition in power struggles. ICA works based on the objective function, which minimizes Integral Time Absolute Error (ITAE). From the results of ICA optimization obtained value $K p=$ 63.1087, $K i=43.2682, K d=9.6038$. Response system, among others, for the settling time of 5.8 and overshoot of -9.098e-05 to 1.111e-09 pu which is the smallest settling time and overshoot value.
\end{abstract}

Keywords - Wind-diesel; ICA; PID; frequency; overshoot

\begin{abstract}
Abstrak - Pengaturan frekuensi beban pada pembangkit listrik tenaga hibrid wind-diesel (PLTH) menjadi hal yang sangat penting agar dapat menunjang kinerja pembangkit. Salah satu metode pengaturan frekuensi beban adalah menggunakan kontroler tambahan seperti Proporsional Integral Derivatif (PID). Penggunaan PID juga mempunyai permasalahan tersendiri, seperti penyetelan nilai gain yang tidak optimal. Dalam penerapannya gain PID ditala secara trial-error, sehingga sulit untuk mendapatkan nilai optimal dari PID. Dalam penelitian ini, diusulkan sebuah metode cerdas yaitu Imperialist Competitive Algorithm (ICA) dalam mencari nilai optimal dari PID. ICA merupakan metode cerdas yang terinspirasi dari kompetisi dalam memperebutkan kekuasaan. ICA bekerja berdasarkan fungsi objektif,
\end{abstract}

*) Penulis korespondensi (Muhammad Ruswandi Djalal) Email: wandi@poliupg.ac.id yaitu meminimalkan Integral Time Absolute Error (ITAE). Dari hasil optimasi ICA didapatkan nilai Kp= 63.1087, $K i=43.2682, K d=9.6038$. Respons sistem yang diperoleh antara lain waktu settling sebesar 5.8 dan overshoot sebesar -9.098e-05 hingga 1.111e-09 pu yang merupakan nilai waktu settling dan overshoot terkecil.

Kata Kunci - Wind-diesel; ICA; PID; frekuensi; overshoot

\section{Pendahuluan}

Seiring dengan meningkatnya kebutuhan manusia, maka kebutuhan energi juga ikut bertambah. Salah satu indikator tersebut adalah terjadinya krisis energi di dunia. Tingkat ketergantungan pada sumber energi fosil terutama minyak bumi menjadi salah satu penyebab dari permasalahan tersebut, dan terlebih sumber cadangan minyak bumi yang semakin terbatas.

Oleh karena itu, diperlukan suatu upaya agar tercipta keseimbangan energi yang baik. Salah satu solusinya adalah pemanfaatan energi alternatif, dengan meningkatkan peran energi terbarukan maka secara tidak langsung menjamin keamanan pasokan energi untuk memenuhi kebutuhan energi nasional yang semakin meningkat secara berkelanjutan, baik untuk kegunaan di bidang pembangkitan energi listrik maupun di bidang transportasi. Seperti diketahui, kegiatan penyediaan tenaga listrik dan transportasi merupakan kegiatan penyediaan sarana dan komoditas penggerak roda perekonomian nasional yang vital dan strategis dalam rangka meningkatkan pasokan energi terbarukan dalam memenuhi kebutuhan energi nasional yang semakin hari semakin meningkat secara efisien, terjangkau, dan berkelanjutan. Pembangkit tenaga listrik hibrida (PLTH) merupakan salah satu alternatif sistem pembangkit yang tepat diaplikasikan pada daerahdaerah yang terisolasi atau sukar dijangkau oleh sistem pembangkit besar seperti jaringan PLN atau PLTD. Sumber utama (primer) PLTH ini memanfaatkan energi terbarukan yang kemudian dikombinasikan dengan genset (generator diesel) sebagai sumber energi 


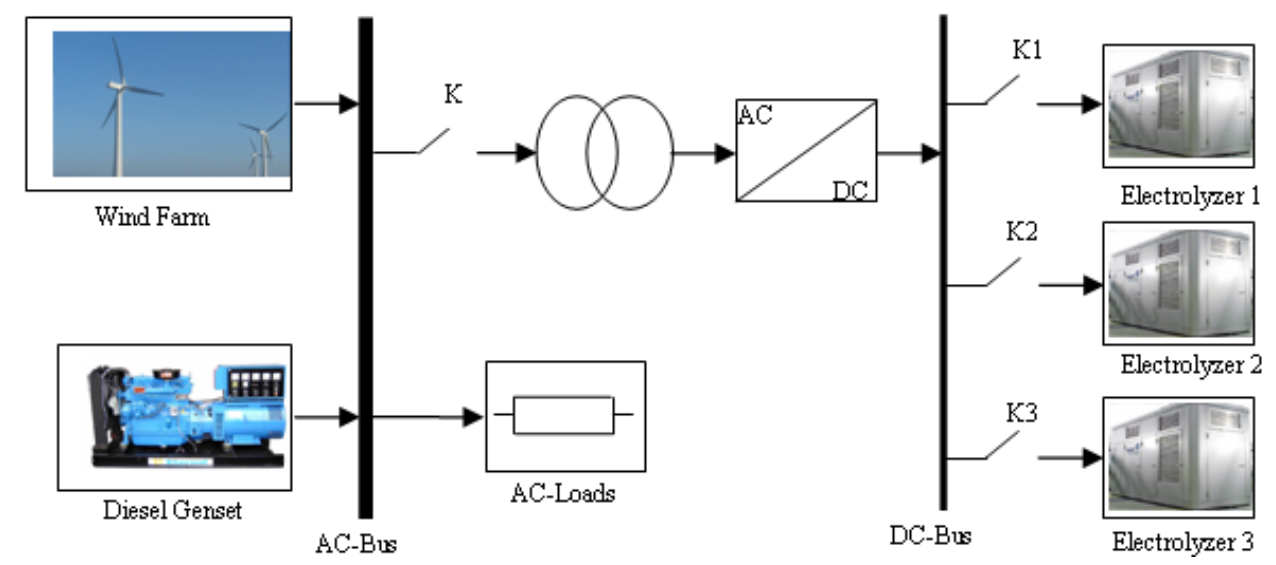

Gambar 1. Konfigurasi pembangkit wind-diesel

sekunder (cadangan). Pada sistem pembangkit PLTH, kombinasi pembangkit energi terbarukan yang digunakan dapat berasal dari energi matahari, angin, dan lain-lain yang dikombinasikan dengan generator diesel sehingga menjadi suatu pembangkit yang lebih efisien, efektif dan handal untuk dapat menyuplai kebutuhan energi listrik yang terisolasi dari PLN atau pusat pembangkit.

Beberapa penelitian telah membahas pengaturan frekuensi pada wind-diesel [1]-[5] untuk mengatasi permasalahan pengaturan frekuensi yang menyebabkan fluktuasi aliran daya pada berbagai jenis pembangkitan sistem hibrida yang terkoneksi. Dari beberapa penelitian tersebut, diketahui masih menggunakan kontroler PID yang ditala secara manual sehingga hasil yang didapatkan belum optimal.

Metode kecerdasan buatan merupakan salah satu teknik optimasi yang dapat menyelesaikan masalah optimasi yang kompleks. Penggunaan metode cerdas dalam sistem tenaga listrik sudah semakin banyak, dan menunjukkan hasil yang memuaskan [6]-[8]. Dalam penelitian tentang pengaturan frekuensi beban, sudah ada beberapa peneliti yang menggunakan metode cerdas untuk optimasi pembangkit, di antaranya El-Fergani dan El-Hameed [9] yang menggunakan kecerdasan buatan berbasis social spider, Dhanalakshmi dan Palawiswami [10] yang menggunakan Anfis, Lal dkk. [11] yang menggunakan differential evolution, Siddik dkk. [12] yang menggunakan logika fuzzy, dan Abidin [13] yang menggunakan algoritma genetika.

Metode kecerdasan buatan berbasis Imperialist Competitive Algorithm (ICA) merupakan salah satu teknik komputasi yang terinspirasi dari kompetisi kekuasaan untuk merebut kekuasaan. Metode ICA untuk optimasi sistem tenaga listrik sudah banyak dilakukan untuk sumber tunggal, seperti Lastomo dkk. [7] untuk optimasi pendulum, Djalal dkk. [8] untuk optimasi penstabil sistem tenaga, Taher dkk. [14] untuk optimasi PID, dan Hunaini dkk. [15] untuk optimasi kontrol steering.

Metode ICA tersebut dapat diterapkan untuk optimasi pembangkit listrik hibrida surya, angin dan diesel. Pembangkit listrik sistem hibrida ini sangat tergantung dari bentuk beban atau fluktuasi pemakaian energi (load profile) yang selama 24 jam distribusi beban tidak merata untuk setiap waktunya. Load profile ini sangat dipengaruhi penyediaan energinya. Permasalahan yang terjadi pada pembangkitan adalah terjadinya frekuensi osilasi yang rendah. Frekuensi harus dapat dijaga kestabilannya agar peralatan dapat beroperasi dengan baik dan efisien. Strategi yang berbeda dapat diterapkan dengan cara mereduksi perbedaan pembangkitan dan beban serta mengatur deviasi frekuensi sistem. Penelitian ini bertujuan untuk melakukan studi sistem kontrol frekuensi beban atau load frequency control (LFC) pada sistem daya hibrida dengan metode cerdas ICA.

\section{Metode Penelitian}

Model dalam studi kasus ini terdiri dari 4 sub sistem, yaitu model dinamik turbin angin, model dinamik diesel, kontrol kecepatan sudut turbin angin dan model dinamik generator. Konfigurasi pembangkit wind-diesel ditunjukkan dalam Gambar 1. Fungsi transfer pembangkit listrik turbin angin dan diesel ditunjukkan dalam Gambar 2. Turbin angin ditunjukkan dalam kotak merah solid, sedangkan diesel dalam kotak biru putusputus.

Metode yang digunakan untuk mengoptimalkan parameter PID dalam pengaturan frekuensi sistem daya hibrida adalah metode ICA, seperti halnya Fassami [16] untuk optimasi superconducting magnetic energy storage (SMES). Fungsi objektif yang digunakan adalah dengan integral time absolut error (ITAE) [17] yang dinyatakan dalam Persamaan 1.

$$
\text { ITAE }=\int_{0}^{t} t|\Delta \omega(t)| d t
$$

Parameter PID yang ditala oleh ICA adalah Kp, Ki dan Kd. Model PID ICA ini dinyatakan dalam Simulink Matlab 2013. Respons frekuensi model PID ICA ini dibandingkan dengan respons dari model pembangkit tanpa kontrol dan PID trial-error. Respons frekuensi untuk pembangkit tanpa kontrol, PI trial-error dan PID ICA dilakukan dengan menggunakan model pembangkit 


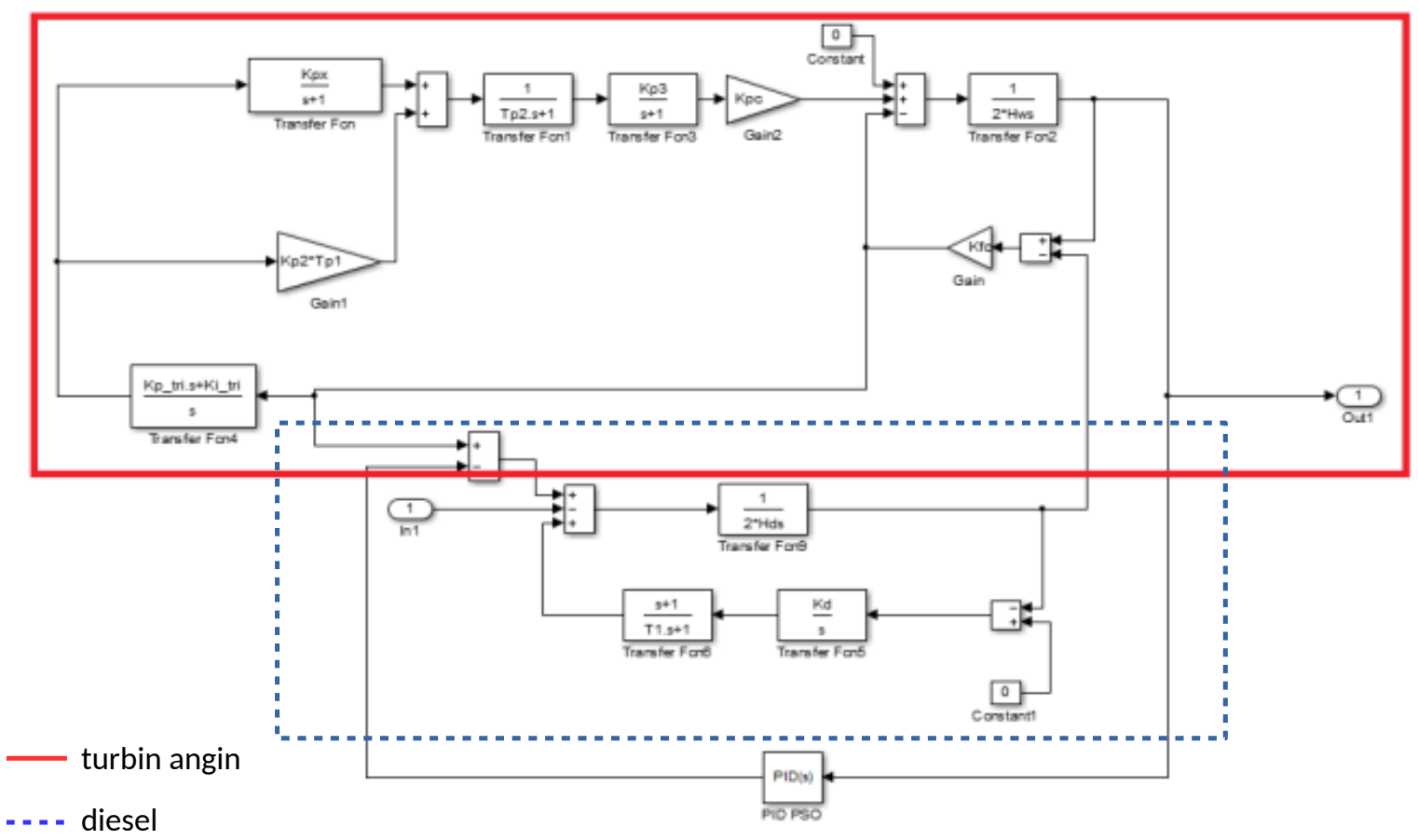

Gambar 2. Pemodelan pembangkit listrik turbin angin dan diesel

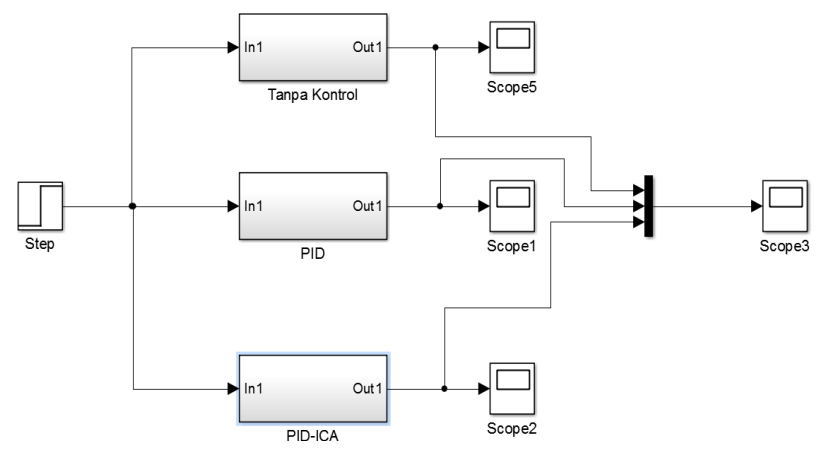

Gambar 3. Pemodelan Simulink semua model

turbin angin dan diesel seperti Gambar 2. Yang membedakannya adalah di blok umpan balik PID-nya. Model pertama adalah tanpa kontrol (umpan balik langsung) serta model kedua dan ketiga adalah dengan kontrol PI yang ditala secara trial-error dan PID yang ditala menggunakan metode cerdas ICA. Gambar 3 menunjukkan pemodelan keseluruhan sistem.

Diagram alir metode ICA ditunjukkan dalam Gambar 4. Data parameter ICA dinyatakan dalam Tabel 1. Parameter angin diesel dinyatakan dalam Tabel 2.

Kestabilan sistem dinyatakan dengan melihat nilai eigen sesuai dengan kriteria dalam Persamaan 2 [17]. Jika nilai eigen negatif untuk komponen real $(\alpha)$, maka grafik akan turun (konvergen) mendekati nilai 0 . Kondisi seperti ini menunjukkan sistem akan teredam dengan baik. Jika nilai eigen positif, maka respons sistem akan divergen menjauhi nilai 0 sehingga sistem tidak akan pernah kembali ke kondisi steady state. Jika nilai eigen komponen real $(\alpha=0)$, maka sistem akan berosilasi harmonik dan berarti sistem tidak akan pernah
Tabel 1. Parameter metode ICA [9]

\begin{tabular}{cc}
\hline Parameter & Nilai \\
\hline Jumlah Countries & 50 \\
InitialImperialists & 5 \\
Decades & 50 \\
RevolutionRate & 0.3 \\
AssimilationCoefficient & 2 \\
AssimilationAngleCoefficient & 0.5 \\
Zeta & 0.02 \\
Damp Ratio & 0.99 \\
Uniting Threshold & 0.02 \\
\hline
\end{tabular}

Tabel 2. Parameter wind-diesel [1]

\begin{tabular}{cc}
\hline Parameter & Nilai \\
\hline $\mathrm{Hw}_{\mathrm{w}}$ & $3.5 \mathrm{~s}$ \\
$\mathrm{H}_{\mathrm{d}}$ & $8.5 \mathrm{~s}$ \\
$\mathrm{~K}_{\mathrm{FC}}$ & $16.2 \mathrm{~Hz}$ \\
$\mathrm{~K}_{\mathrm{D}}$ & $16.5 \mathrm{~Hz}$ \\
$\mathrm{ZK}_{\mathrm{pc}}$ & 2.0 \\
$\mathrm{~K}_{\mathrm{p} 1}$ & 4 \\
$\mathrm{~K}_{\mathrm{p} 2}$ & 1.25 \\
$\mathrm{~T}_{\mathrm{p} 1}$ & $0.6 \mathrm{~s}$ \\
$\mathrm{~T}_{\mathrm{p} 2}$ & $0.041 \mathrm{~s}$ \\
\hline
\end{tabular}

stabil. Sistem dikatakan stabil apabila seluruh komponen real dari nilai eigen bernilai negatif [17].

$$
y(t)=\frac{|K(a+j b)|}{b} e^{a t} \sin (b t+\alpha)
$$

\section{Hasil dan Pembahasan}

Hasil konvergensi optimasi algoritma ICA dalam mencari parameter optimal kontroler PID untuk 


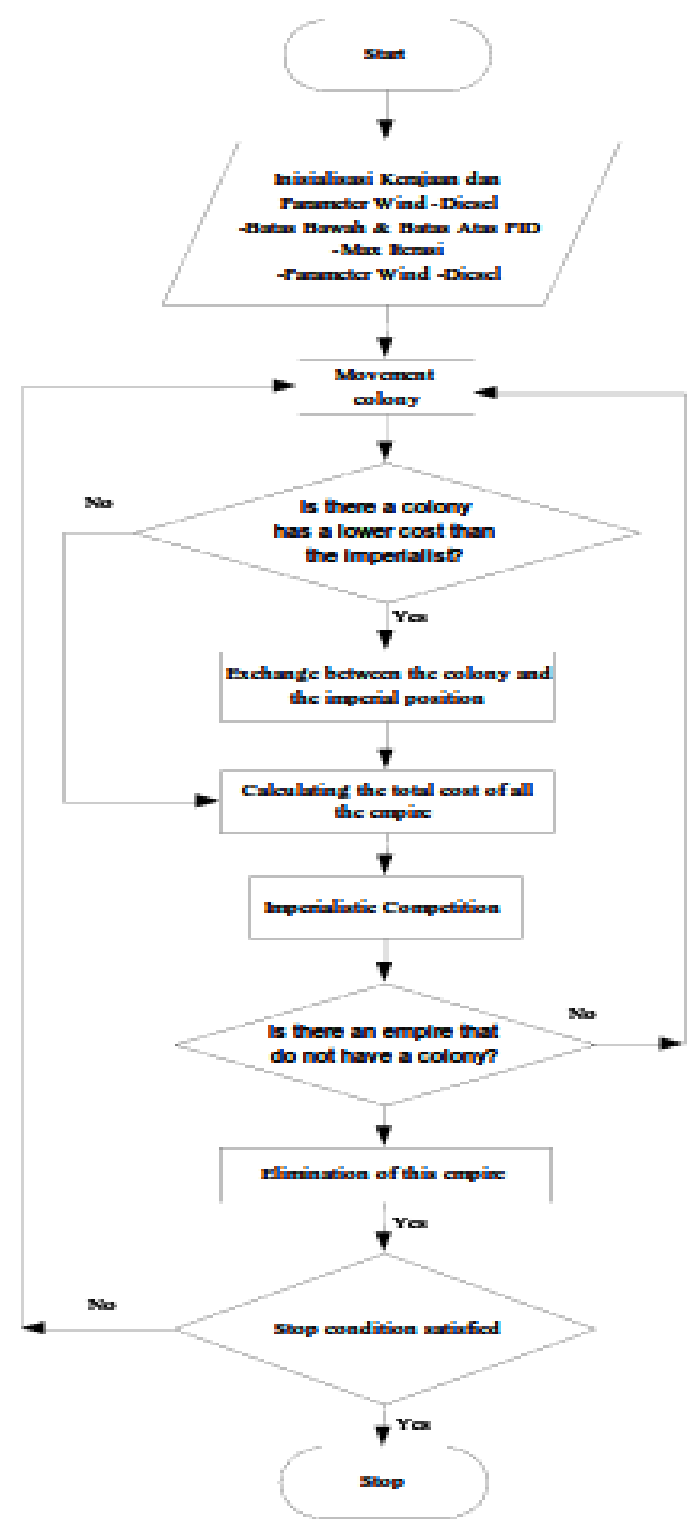

Gambar 4. Diagram alir ICA [7]

pembangkit hibrida angin diesel ditunjukkan dalam Gambar 5. Dari hasil optimasi tersebut menunjukkan bahwa ICA sangat cepat dalam mencari nilai optimal dari PID. Hal ini terlihat bahwa ICA sudah menemukan solusi optimal pada iterasi ke-6 dengan fungsi fitness sebesar 0.000156332422918444. Hasil penalaan PID dapat dilihat pada Tabel 3 yang merupakan hasil optimasi PID ICA, yaitu menghasilkan $\mathrm{Kp}=63,1087$, $\mathrm{Ki}=43,2682$ dan $\mathrm{Kd}=9,6038$. Nilai parameter ini digunakan di model pembangkit dengan kontroler PID ICA. Tiap model merespons perubahan beban sebesar $0.05 \mathrm{pu}$.

\section{A. Respons Frekuensi Wind-Diesel Tanpa Kontroler}

Simulasi yang pertama adalah simulasi loop terbuka wind-diesel tanpa kontroler. Simulasi loop terbuka digunakan untuk meninjau respons sistem tanpa kontroler, dan dijadikan referensi untuk merancang desain sistem kontrol wind-diesel dengan fungsi objektif

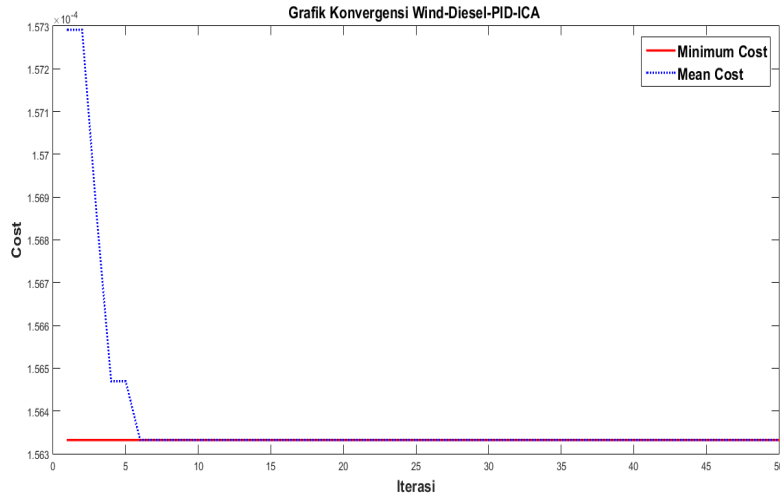

Gambar 5. Grafik konvergensi ICA

Tabel 3. Hasil penalaan parameter PID

\begin{tabular}{cccc}
\hline \multirow{2}{*}{ Parameter } & \multicolumn{2}{c}{ Konstrain } & \multirow{2}{*}{ Hasil ICA } \\
& Bawah & Atas & \\
\hline$K p$ & 80 & 90 & 63.1087 \\
$K i$ & 50 & 60 & 43.2682 \\
$K d$ & 10 & 15 & 9.6038 \\
\hline
\end{tabular}

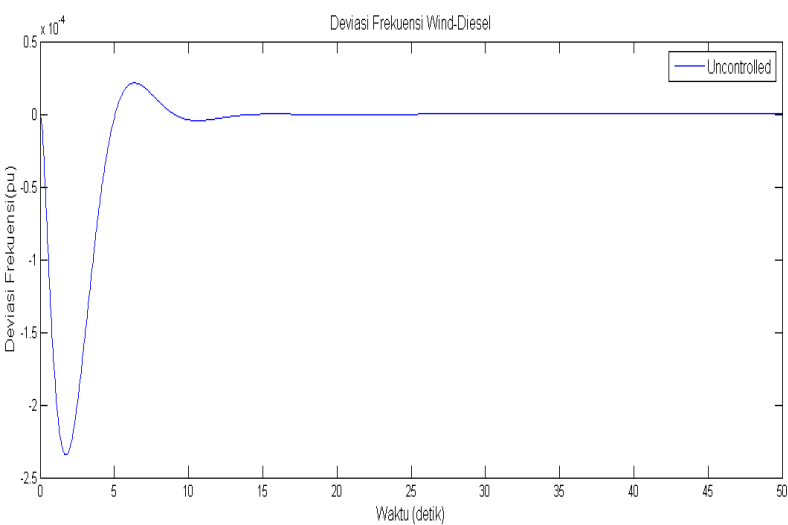

Gambar 6. Hasil frekuensi wind-diesel tanpa kontroler

meminimalkan ITAE seperti Persamaan 1. Grafik frekuensi hasil simulasi loop terbuka wind-diesel tanpa kontroler ditunjukkan dalam Gambar 6.

Respons sistem tanpa kontrol mempunyai nilai overshoot dan waktu settling frekuensi wind-diesel yang sangat besar seperti ditunjukkan dalam Tabel 4, yaitu sebesar $-2.344 \mathrm{e}-04$ hingga $2.15 \mathrm{e}-05$ pu dan 13.2 detik. Nilai eigen-nya ditunjukkan dalam Gambar 7. Model pembangkit ini tidak disarankan karena masih terdapat osilasi yang cukup besar sehingga kinerja pembangkit tidak optimal.

\section{B. Respons Frekuensi Wind-Diesel denga Kontroler PID Trial-Error}

Respons frekuensi loop terbuka dibandingkan dengan PID yang konvensional, yaitu menggunakan kontrol PID trial-error. Respons frekuensi kontrol PID trial-error ditunjukkan dalam Gambar 8. Nilai overshoot yang terjadi dan waktu settling-nya dapat dilihat pada Tabel 5, yaitu sebesar $-2.227 \mathrm{e}-04$ hingga $1.076 \mathrm{e}-05$ pu dan 12.8 detik. Nilai eigen-nya ditunjukkan dalam Gambar 9. 
Tabel 4. Nilai overshoot dan waktu settling tanpa kontrol

\begin{tabular}{cc}
\hline Karakteristik & Nilai \\
\hline Overshoot $(\mathrm{pu})$ & $-0.0002344 \& 2.15 \mathrm{e}-05$ \\
Waktu settling (detik) & 13.2 \\
& $-39.0044+0.0000 \mathrm{i}$ \\
& $-24.3534+0.0000 \mathrm{i}$ \\
& $-3.7197+0.0000 \mathrm{i}$ \\
Eigen & $-1.3472+0.0000 \mathrm{i}$ \\
& $-0.4696+0.6981 \mathrm{i}$ \\
& $-0.4696-0.6981 \mathrm{i}$ \\
& $-0.2978+0.0000 \mathrm{i}$ \\
& $0.0043+0.0000 \mathrm{i}$ \\
\hline
\end{tabular}

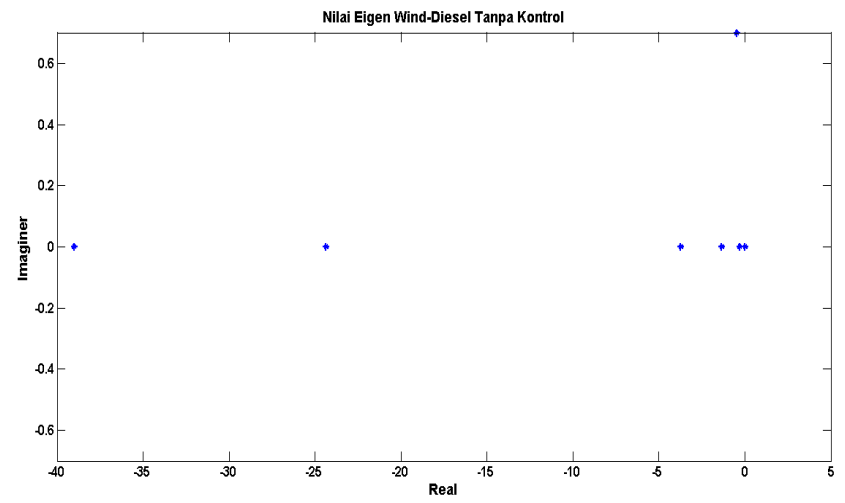

Gambar 7. Nilai eigen wind-diesel tanpa kontrol

Jika dibandingkan dengan respons frekuensi sistem yang tanpa kontroler, nilai overshoot-nya menjadi lebih kecil. Namun, model ini tidak direkomendasikan digunakan sebagai pengontrol. Kinerja pembangkit pada jenis ini masih bisa untuk ditingkatkan dengan penalaan optimal dari PID.

\section{Respons Frekuensi Wind-Diesel dengan Kontroler PID-ICA}

Respons frekuensi wind-diesel menggunakan kontroler PID ICA ditunjukkan dalam Gambar 10. Nilai overshoot dan nilai waktu settling-nya dinyatakan dalam Tabel 6, yaitu sebesar $-9.098 \mathrm{e}-05$ hingga $1.111 \mathrm{e}-09 \mathrm{pu}$ dan 5.8 detik. Nilai negatif untuk komponen real nilai eigen menunjukkan bahwa sistem stabil sesuai dengan Persamaan 2 [17]. Sistem ini memiliki lima eigen value dan seluruhnya bernilai negatif, maka sistem ini dikatakan stabil dalam keadaan steady state (tunak).

Perbandingan respons frekuensi dari ketiga sistem ditunjukkan dalam Gambar 12. Dari tiga model sistem pembangkit listrik hibrid wind-diesel tersebut dapat dinyatakan bahwa suatu pembangkit listrik wind-diesel mutlak memerlukan kontroler sebagai peredam osilasi frekuensi yang terjadi akibat perubahan beban seperti yang telah dilakukan oleh [1]-[5]. Model kontroler PID ICA dalam penelitian ini memiliki pengaruh yang signifikan dalam peredaman osilasi tersebut. Nilai waktu settling-nya sebesar 5.8 detik merupakan nilai waktu settling tercepat dan nilai overshoot-nya sebesar -9.098e-05 hingga $1.111 \mathrm{e}-09$ pu merupakan nilai

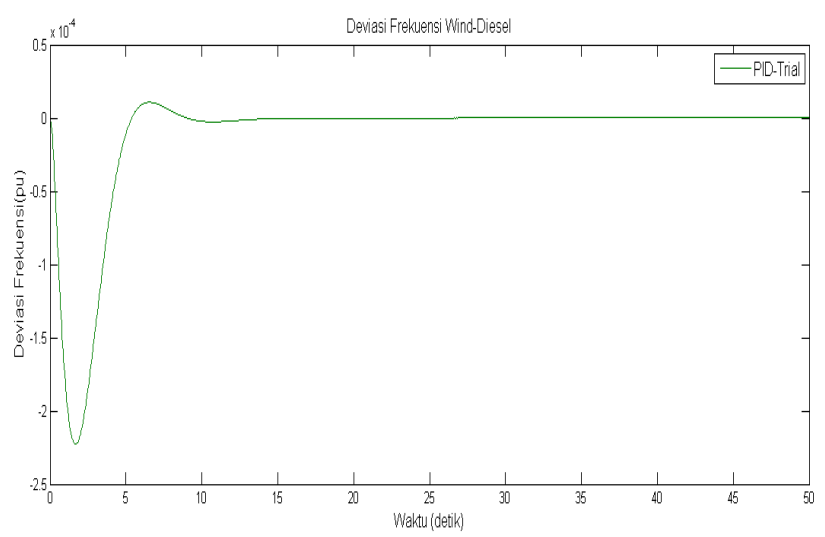

Gambar 8. Respons frekuensi wind-diesel PID trialerror

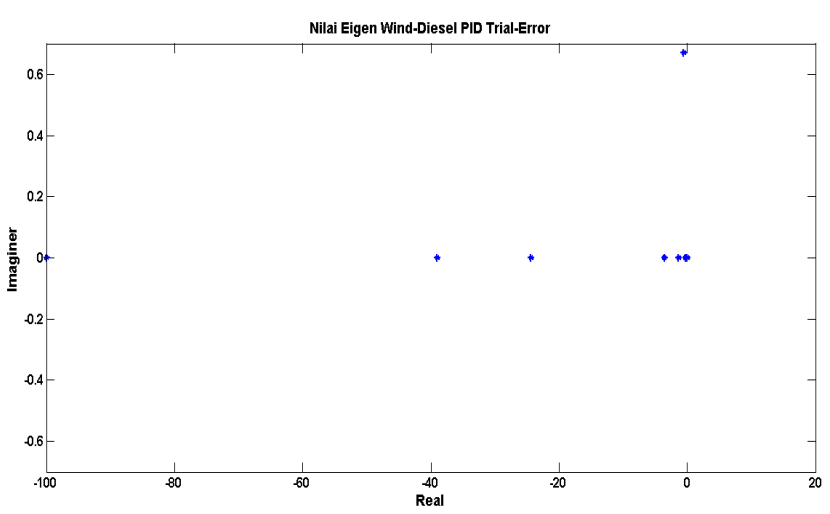

Gambar 9. Nilai eigen wind-diesel PID trial-error

Tabel 5. Nilai overshoot dan waktu settling PID trialerror

\begin{tabular}{cc}
\hline Karakteristik & Nilai \\
\hline Overshoot $(\mathrm{pu})$ & $-0.0002227 \& 1.076 \mathrm{e}-05$ \\
Waktu settling (detik) & 12.8 \\
& $-99.9994+0.0000 \mathrm{i}$ \\
& $-39.0047+0.0000 \mathrm{i}$ \\
& $-24.3537+0.0000 \mathrm{i}$ \\
Eigen & $-3.5745+0.0000 \mathrm{i}$ \\
& $-1.3492+0.0000 \mathrm{i}$ \\
& $-0.5426+0.6699 \mathrm{i}$ \\
& $-0.5426-0.6699 \mathrm{i}$ \\
& $-0.2950+0.0000 \mathrm{i}$ \\
& $0.0043+0.0000 \mathrm{i}$ \\
& $0.0000+0.0000 \mathrm{i}$ \\
\hline
\end{tabular}

overshoot terkecil dari model kontroler yang lain. Model kontroler PID ICA yang diterapkan dalam [7], [8], [14]-[16], juga cocok untuk diterapkan di sistem pembangkit hibrida wind-diesel.

\section{Kesimpulan}

Metode sistem cerdas PID ICA dapat diterapkan pada sistem kontrol LFC untuk memperbaiki respons frekuensi di sebuah sistem pembangkit hibrida winddiesel. Dengan penalaan parameter yang tepat, yaitu Kp 63,1087, Ki 43,2682 dan Kd 9,6038, kontrol PID ICA dapat menghasilkan respons frekuensi yang paling baik dibandingkan sistem tanpa kontroler dan PID trial-error 


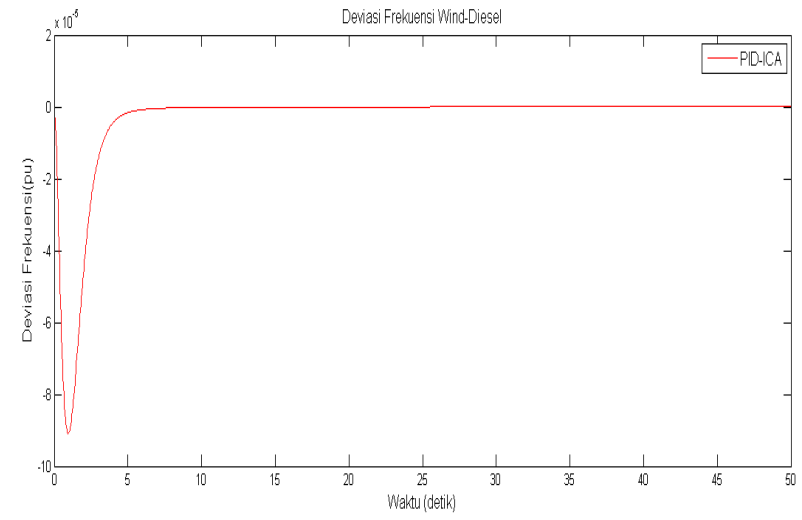

Gambar 10. Respons frekuensi wind-diesel yang dilengkapi kontroler PID ICA

Tabel 6. Nilai overshoot dan waktu settling PID ICA

\begin{tabular}{cc}
\hline Karakteristik & Nilai \\
\hline Overshoot $(\mathrm{pu})$ & $-9.098 \mathrm{e}-05 \& 1.111 \mathrm{e}-09$ \\
Waktu settling (detik) & 5,8 \\
Eigen & $-98.5988+0.0000 \mathrm{i}$ \\
& $-38.9466+0.0000 \mathrm{i}$ \\
& $-24.3247+0.0000 \mathrm{i}$ \\
& $-2.4867+1.9067 \mathrm{i}$ \\
$-2.4867-1.9067 \mathrm{i}$ \\
$-1.2999+0.0000 \mathrm{i}$ \\
$-1.1920+0.0000 \mathrm{i}$ \\
$-0.3264+0.0000 \mathrm{i}$ \\
& $0.0044+0.0000 \mathrm{i}$ \\
& $0.0000+0.0000 \mathrm{i}$ \\
\hline
\end{tabular}

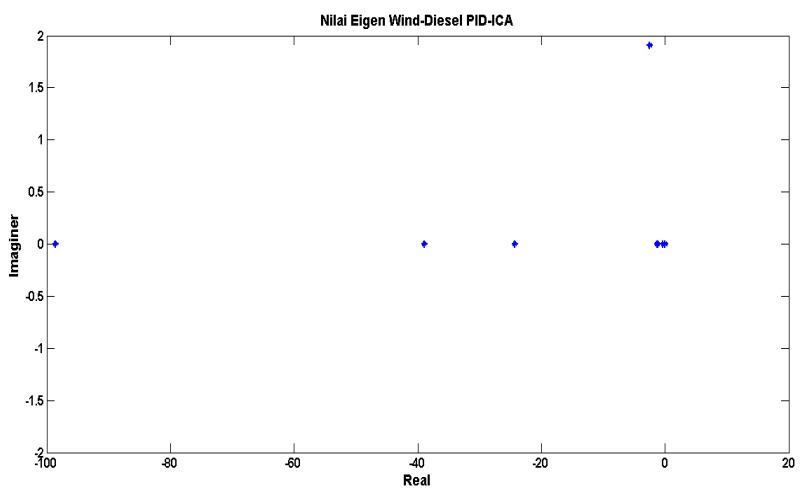

Gambar 11. Nilai eigen wind-diesel PID ICA

dilihat dari nilai overshoot dan waktu settling-nya. Sistem ini juga menghasilkan sistem yang stabil dalam keadaan tunak.

\section{Daftar Pustaka}

[1] T. Bhatti, A. Al-Ademi, and N. Bansal, "Load Frequency Control of Isolated Wind Diesel Hybrid Power Systems," Energy conversion and management, vol. 38, no. 9, pp. 829-837, 1997.

[2] H. Junrui, H. Yuchun, and T. Wen, "Load Frequency Control of Wind Diesel Hybrid Power Systems via Predictive Control," in 2012 31st

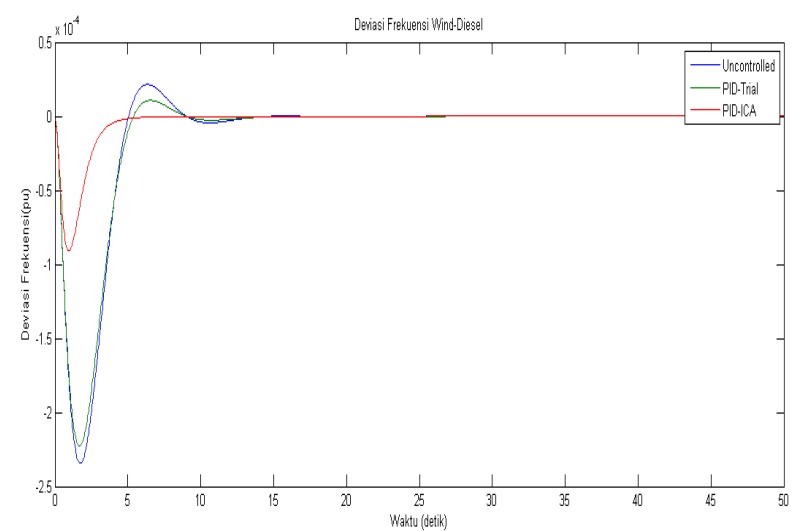

Gambar 12. Grafik perbandingan respons frekuensi ketiga kontroler

Chinese Control Conference (CCC), 2012, pp. 6698-6703.

[3] M. S. Citraningrum, M. Ashari, and F. A. Pamuji, "Design of Frequency Control on Hybrid Winddiesel with PID-firefly," in 2015 International Electronics Symposium (IES), 2015, pp. 26-30.

[4] S. Soedibyo, F. A. Pamuji, and M. Ashari, "Control Design of Wind Turbine System Using Fuzzy Logic Controller for Middle Voltage Grid," Indonesian Journal of Electrical Engineering and Computer Science, vol. 13, no. 3, pp. 476-482, 2015.

[5] W. Tan and J. Zhang, "Load Frequency Control for Wind-diesel Hybrid Systems," in 2011 30th Control Conference (CCC), 2011, pp. 5126-5131.

[6] M. R. Djalal, D. Ajiatmo, A. Imran, and I. Robandi, "Desain Optimal Kontroler PID Motor DC Menggunakan Cuckoo Search Algorithm," SENTIA 2015, vol. 7, no. 1, 2015.

[7] D. Lastomo, H. Setiadi, and M. R. Djalal, "Design Controller of Pendulum System using Imperialist Competitive Algorithm," Jurnal Intek Politeknik Negeri Ujung Pandang, vol. 4, no. 1, pp. 53-59, 2017.

[8] M. R. Djalal, A. Imran, and I. Robandi, "Optimal Placement and Tuning Power System Stabilizer using Participation Factor and Imperialist Competitive Algorithm in $150 \mathrm{kV}$ South of Sulawesi System," in 2015 International Seminar on Intelligent Technology and Its Applications (ISITIA), 2015, pp. 147-152.

[9] A. A. El-Fergany and M. A. El-Hameed, "Efficient Frequency Controllers for Autonomous Two-area Hybrid Microgrid System using Social-spider Optimiser," IET Generation, Transmission \& Distribution, vol. 11, no. 3, pp. 637-648, 2017.

[10] R. Dhanalakshmi and S. Palaniswami, "ANFIS based Neuro-Fuzzy Controller in LFC of WindMicro Hydro-Diesel Hybrid Power System," International Journal of computer applications, vol. 42, no. 6, pp. 28-35, 2012.

[11] D. Lal, A. Barisal, and S. Nayak, "Load Frequency Control of Wind Diesel Hybrid Power System using DE Algorithm," in 2016 10th International 
Conference on Intelligent Systems and Control (ISCO), 2016, pp. 1-6.

[12] S. Siddik, A. S. Vinayagam, and R. Gopinath, "Load Frequency Control of a Hybrid Wind Diesel System Using Fuzzy Logic Control," International Journal of Advanced Research in Electrical, Electronics and Instrumentation Engineering, vol. 3, no. 4, pp. 82-87, May 2014.

[13] Z. Abidin, "Pengaturan Frekuensi Beban Hibrid Turbin Angin Diesel dengan Menggunakan Algoritma Genetika," Jurnal Teknika, vol. 2, no. 2, pp. 7-16, 2010.

[14] S. A. Taher, M. H. Fini, and S. F. Aliabadi, "Fractional Order PID Controller Design for LFC in Electric Power Systems using Imperialist
Competitive Algorithm," Ain Shams Engineering Journal, vol. 5, no. 1, pp. 121-135, 2014.

[15] F. Hunaini, I. Robandi, and N. Sutantra, "Lateral and Yaw Motion Control of the Vehicle Using Fuzzy Logic and PID Being Optimied by Firefly Algorithm," Journal of Theoretical and Applied Information Technology, vol. 87, no. 1, 2016.

[16] M. A. Fassamsi, "Optimal Tuning PID Superconducting Magnetic Energy Storage (SMES) Menggunakan Imperialist Competitive Algorithm (ICA) untuk Meredam Osilasi Daya pada Sistem Kelistrikan Jawa Bali 500 kV," Skripsi, Teknik Elektro, Institut Teknologi Sepuluh Nopember, Surabaya, Indonesia, 2010.

[17] K. Ogata, Discrete-time Control Systems Vol. 8. Prentice-Hall Englewood Cliffs, NJ, 1995. 